\title{
Nitrogen and neon retention in plasma-facing materials
}

\author{
M. Rubel ${ }^{\mathrm{a}, *}$, V. Philipps ${ }^{\mathrm{b}}$, L. Marot $^{\mathrm{c}}$, P. Petersson ${ }^{\mathrm{d}}$, A. Pospieszczyk $^{\mathrm{b}}$, B. Schweer $^{\mathrm{b}}$ \\ a Alfvén Laboratory, Royal Institute of Technology, Association EURATOM - VR, Sweden \\ b Institute for Energy Research, Forschungszentrum Jülich, Association EURATOM, Germany \\ ${ }^{\mathrm{c}}$ Department of Physics, University of Basel, Association EURATOM - CRPP, Switzerland \\ d Ångström Laboratory, Uppsala University, Association EURATOM - VR, Uppsala, Sweden
}

\section{A R T I C L E I N F O}

Article history:

Available online 17 September 2010

\begin{abstract}
A B S T R A C T
Tungsten plate was exposed in the TEXTOR tokamak during nitrogen-assisted discharges. In order to determine material mixing on tungsten, the plate was examined ex situ with ion beam analysis techniques including time-of-flight heavy ion elastic recoil detection analysis and also with X-ray photoelectron spectroscopy. Nitrogen content in the range from $1.3 \times 10^{15}$ to $3.4 \times 10^{15} \mathrm{~cm}^{-2}$ is measured in the outermost surface layer $(20 \mathrm{~nm})$ of the $\mathrm{W}$ plate. Photoelectron spectroscopy detects nitrogen both in the elemental and compound form, i.e. tungsten nitride $\left(\mathrm{WN} / \mathrm{W}_{2} \mathrm{~N}\right)$. Nitrogen is measured even in hot areas free from deuterium. Also neon co-implantation into the plasma-facing components has been identified following Ne-cooled pulses.
\end{abstract}

(c) 2010 EURATOM. Published by Elsevier B.V. All rights reserved.

\section{Introduction}

Impurity seeding is a method for improved edge radiation (cooling) especially in operation with high-Z plasma-facing components (PFC) [1-5]. The injection of neon (Ne), argon (Ar), or nitrogen $\left(\mathrm{N}_{2}\right)$ is performed for that purpose. The injection of even heavier noble gases, i.e. $\mathrm{Kr}$ or $\mathrm{Xe}$, is considered to be more beneficial from the point of view of edge cooling but their application in the neutron environment would add to the machine contamination by radioactive transmutation products. It would also be an additional burden for the gas separation system in the tritium plant. Massive puff of $\mathrm{Ne}$ or $\mathrm{Ar}$ is a key element in the development of disruption mitigation techniques [6,7]. Nitrogen-assisted discharges are also considered as a route to reduction of fuel inventory. Encouraging results have been obtained in laboratory experiments [8-10], but no beneficial effects have been achieved in a tokamak or in a toroidal plasma-wall interaction simulator [11]. Among many issues related to the injection is the in-vessel residence of gas by implantation, codeposition or by compound formation with the PFC material $[2,12,13]$. The latter may become important in the case of nitrogen-tungsten combination. To address the change of PFC surface morphology in the presence of nitrogen or neon, dedicated experiments were performed in the TEXTOR tokamak.

\footnotetext{
* Corresponding author. Address: School of Electrical Engineering, Fusion Plasma Physics, KTH, Teknikringen 31, SE-100 44 Stockholm, Sweden. Tel.: +46 879060 93; fax: +4687906574

E-mail address: rubel@kth.se (M. Rubel).
}

\section{Experimental}

The experiments were performed with: (a) bulk tungsten (W) plates acting as a test limiter during discharges with nitrogen injection and (b) graphite probes exposed in the presence of neon injection. The tungsten plates were mounted on a roof-shaped holder, like the one presented in [14], and inserted into the TEXTOR tokamak through a limiter lock from the bottom of the machine. The top of the limiter was positioned $1.5 \mathrm{~cm}$ deep in the scrapeoff-layer (SOL) at $r=47.5 \mathrm{~cm}$ with the main toroidal pump limiter (ALT-II) at $a=46 \mathrm{~cm}$. The total exposure comprised 22 shots auxiliary heated with $1.25 \mathrm{MW}$ by neutral beam injection (NBI). Nitrogen $\left(\mathrm{N}_{2}\right)$ gas was injected during 13 discharges from the main gas injection module. In total this was 21.0 mbarl introduced, the equivalent to $5643 \times 10^{20} \mathrm{~N}_{2}$ molecules $\left(2.62 \times 10^{-3} \mathrm{~g}\right)$. In the edge region, spectroscopy measurements were focused both on the ALT-II limiter $\left(\mathrm{H}_{\alpha}, \mathrm{H}_{\beta}, \mathrm{H}_{\gamma}, \mathrm{H}_{\delta}, \mathrm{CII}\right.$ and NII) and on the test limiter where NII, WI, CII and $\mathrm{H}_{\gamma}$ lines were recorded. For the determination of the relative nitrogen fluxes (with respect to $\mathrm{H}_{\delta}$ ) NII line $500.1 \mathrm{~nm}$ has been used. The fluxes at the SOL were estimated from the S/XB line ratio: nitrogen accounted for $5-10 \%$ of the total flux.

During neon-assisted discharges a graphite collector probe made of EK98 graphite was located typically at a radius of $r=49 \mathrm{~cm}$, i.e. $3 \mathrm{~cm}$ deep in the SOL. Exposures were performed during discharges with a molybdenum test limiter; line-averaged plasma density $n_{e}$, in the range from $4 \times 10^{19} \mathrm{~m}^{-3}$ to $6 \times 10^{19} \mathrm{~m}^{-3}$ and NBI heating power of about $3 \mathrm{MW}[15]$.

The exposures were followed by comprehensive surface studies performed by means of sputter-assisted X-ray photoelectron spectroscopy (XPS) and ion beam analysis (IBA). The selected methods allowed both for depth profiling and determination of the surface 


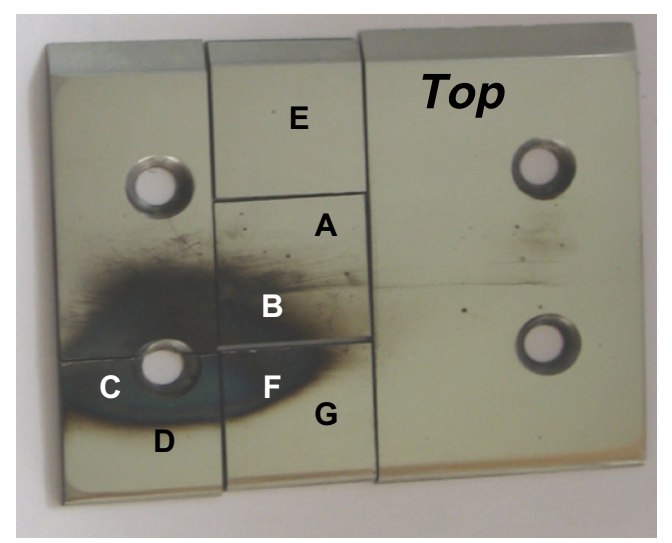

Fig. 1. Tungsten plate sectioned after the exposure during the $\mathrm{N}_{2}$ puffing experiment. The numbering shows the respective samples and points analysed with XPS and ToF-HIERDA.

chemical state, i.e. the information on compound formation. Fig. 1 shows the plate sectioned for the examination. Points (A)-(D) were analysed with XPS, whereas Points (E) $-(G)$ with IBA. The aim was to compare the composition in the region coated with a carbon co-deposit with the area free of deposition. XPS at the University of Basel was focused on the analysis of chemical shift of the following core level: W4f, O1s, C1s and N1s. Time-of-Flight Heavy Ion Elastic Recoil Detection (ToF-HIERDA) [16] was performed at the Tandem Accelerator Laboratory (Uppsala University) using a $40 \mathrm{MeV}^{127} \mathrm{I}^{9+}$ ion beam that impinged on the sample at the angle of $22.5^{\circ}$. This heavy ion produces recoils in the forward direction that can enter the time-of-flight tube located at $135^{\circ}$ with respect to the incoming beam. The tube consists of two very thin carbon foils and a solid-state energy detector. When the recoiled species passes through the foils a signal is triggered and the flight time can be measured. To reduce the noise, the signal from the second foil is used as the start signal for the timing and the signal from the first detector is delayed and then used as the stop signal [16]. Finally the total remaining energy of the recoil is collected by the solid-state detector. The reversed flight time and the energy gives banana-shaped traces for each recoiled mass from which the depth distribution can be calculated for smooth surfaces [17]. The depth range is limited by the shallow interaction range of heavy ions to about $400 \mathrm{~nm}$. A clear benefit of ToF-HIERDA is related to the excellent separation for light elements such as Be, B, C and $\mathrm{N}$, which is very important in studies of surfaces exposed in a tokamak with carbon walls.

\section{Results and discussion}

\subsection{Nitrogen retention}

Plots in Fig. 2 show the evolution of spectroscopy signals during consecutive discharges with nitrogen injection: W(I) line intensity at $400.9 \mathrm{~nm}$ and $\mathrm{N}$ (II) line at $500.1 \mathrm{~nm}$. The duration of NBI pulses and the $\mathrm{N}_{2}$ injection point is marked on the graphs. For the clarity of presentation on a small graph, plots for only three discharges are shown. In Table 1 there are listed experimental parameters such as the line-averaged density $\left(n_{e}\right)$ and the amount of injected $N_{2} . W(I)$ signals in Fig. 2a are plotted for the entire discharge duration. Traces for nitrogen in Fig. $2 \mathrm{~b}$ are shown only for the period preceding the actual $\mathrm{N}_{2}$ injection as the aim is to show the "memory" effect. It reveals the gradual shot-by-shot increase of the N(II) signal thus indicating that after each discharge a certain portion of nitrogen remained in the torus being either adsorbed or co-implanted in PFC. This observation is important for the interpretation of the $\mathrm{W}(\mathrm{I})$
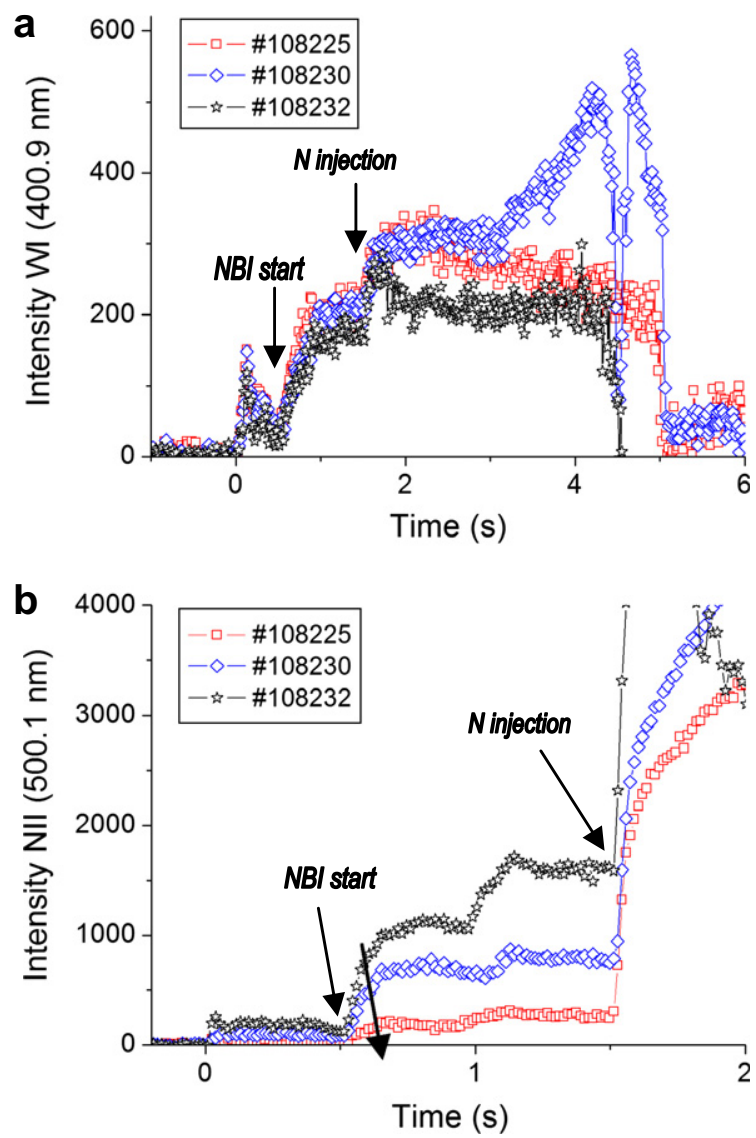

Fig. 2. Spectroscopy signals recorded during the nitrogen puffing experiment: (a) $\mathrm{W}(\mathrm{I})$ line at $400.9 \mathrm{~nm}$ and (b) $\mathrm{N}(\mathrm{II})$ line at $500.1 \mathrm{~nm}$.

Table 1

Experimental parameters during the nitrogen injection: line-averaged density and injected amount.

\begin{tabular}{lll}
\hline Discharge & Density $\left(10^{19} \mathrm{~m}^{-3}\right)$ & $\mathrm{N}_{2}$ injection (mbarl) \\
\hline 108224 & 3.0 & 2.2 \\
108225 & 3.0 & 2.4 \\
108230 & 3.0 & 2.4 \\
108231 & 3.0 & 1.5 \\
108232 & 4.0 & 1.0 \\
\hline
\end{tabular}

signals. The emission increases in consecutive shots despite the fact that the density and the amount injected are the same, e.g. pulses 108225 and 108230 . Lower emission is measured for a shot with the higher density $\left(108232, n_{e}=4 \times 10^{19} \mathrm{~m}^{-3}\right)$ when compared to shots with lower density (108224, 108230, $n_{e}=3 \times 10^{19} \mathrm{~m}^{-3}$ ). It is related to the decrease of erosion rate with the increased density as discussed several times in the past $[18,19]$.

Surface morphology of the plate was examined to determine the $\mathrm{N}$ retention and the chemical state of nitrogen and tungsten. Fig. 3 shows the ToF-HIERDA spectrum recorded at Point G (see Fig. 1), i.e. in the area not coated with the carbon-rich co-deposit. The technique is very sensitive, therefore, all elements present in the sample - from $\mathrm{H}$ to $\mathrm{W}$ - are visible. This also includes iodine (I) that has Scattered off the $\mathrm{W}$ surface.

The main result obtained with HIERDA is the detection of nitrogen in the $\mathrm{W}$ plate: from $1.3 \times 10^{15}$ to $3.4 \times 10^{15} \mathrm{~N}$ at $\mathrm{cm}^{-2}$ in the surface layer $(20 \mathrm{~nm})$. Nitrogen is found even in hot areas free from deuterium (Point $\mathrm{E}$ ). It shows that nitrogen from the gas puff is coimplanted into the $\mathrm{W}$ surface. Besides tungsten and nitrogen, the 


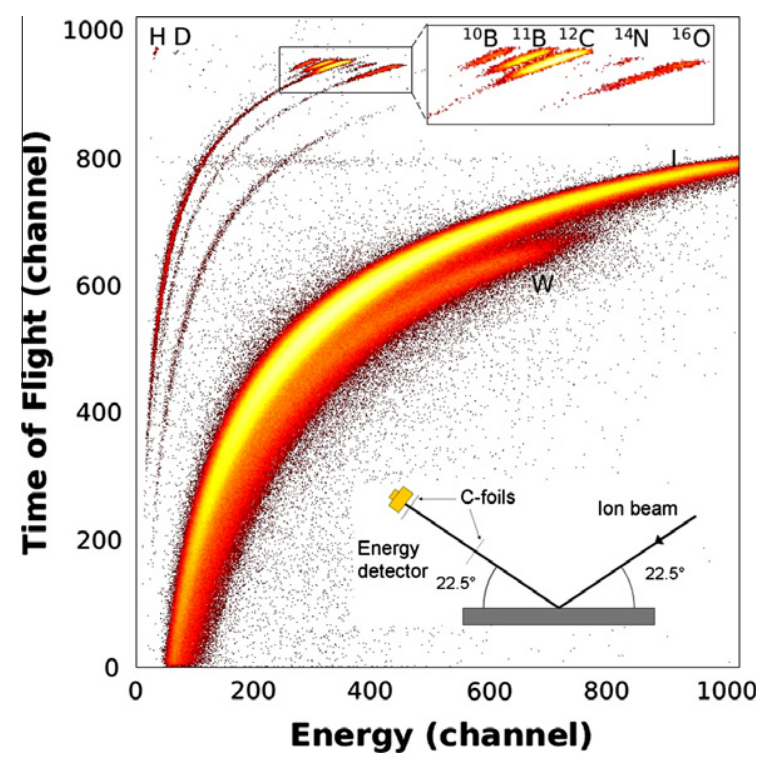

Fig. 3. ToF-HIERDA spectrum recorded on the tungsten plate in Point $\mathrm{G}$ without a thick co-deposit. As inlays a magnification of elements from $\mathrm{B}$ to $\mathrm{O}$ are shown and a schematic view of the set up.

Table 2

Concentrations of light elements detected with ToF-HIERDA on the tungsten plate in areas with and without thick carbon deposit. All concentration are $10^{15} \mathrm{~cm}^{-2}$.

\begin{tabular}{lll}
\hline Element & Point G & Point F \\
& No deposit & With deposit \\
\hline D & 0.5 & 1.3 \\
B & 4.7 & 66 \\
C & 22 & 138 \\
N & 1.3 & 3.4 \\
O & 8.0 & 21 \\
\hline
\end{tabular}

other elements are: carbon, oxygen boron and deuterium. Quantitative results for the analysis of Points F and $G$ is in Table 2. In comparative measurement performed on a not exposed reference $\mathrm{W}$ plate no nitrogen above the detection limit of HIERDA was found.

$\mathrm{X}$-ray photoelectron spectra in Fig. $4 \mathrm{a}$ and $\mathrm{b}$ - recorded for Points A and B - are the survey spectra of the surface on the asexposed plate and after sputter cleaning for 10 min with $\mathrm{Ar}^{+}$ $(2.5 \mathrm{keV})$, respectively. In all of them N1s core level is present. Detailed analysis of the N1s line position has shown its shift in the area without a deposit towards lower binding energy $397.7 \mathrm{eV}$ characteristic for the tungsten nitride compounds, i.e. WN and $\mathrm{W}_{2} \mathrm{~N}$ [20]; this is shown in Fig. 4c. The deconvolution of the W4f shows one component at binding energy of $32.4 \mathrm{eV}$ corresponding to the nitride. The other compounds detected on the plate and deconvoluted from W4f, $\mathrm{C} 1 \mathrm{~s}$ and $\mathrm{01s}$ are carbide (WC) and some traces of tri-oxide $\left(\mathrm{WO}_{3}\right)$ thus confirming previous studies of material mixing on PFC from TEXTOR [21-23]. In the analysis of a not exposed $\mathrm{W}$ plate only adsorbed nitrogen was found and it was fully removed by sputtering. Its amount is $2-3$ times smaller than on the exposed plate.

In summary, the XPS data show that nitrogen occurs in the surface layer (10-20 nm) both in the elemental and compound form, i.e. tungsten nitride $\left(\mathrm{WN} / \mathrm{W}_{2} \mathrm{~N}\right)$. From some areas on the plate nitrogen is removed from the surface by $\mathrm{Ar}^{+}$sputter cleaning. This indicates the presence of implanted or chemically bound $\mathrm{N}$ in the layer exceeding 10-20 $\mathrm{nm}$ in depth. Also other core levels are present in the spectra: iron Fe2p and boron B1s. The result is in full agreement with ToF-HIERDA. These elements were eroded from

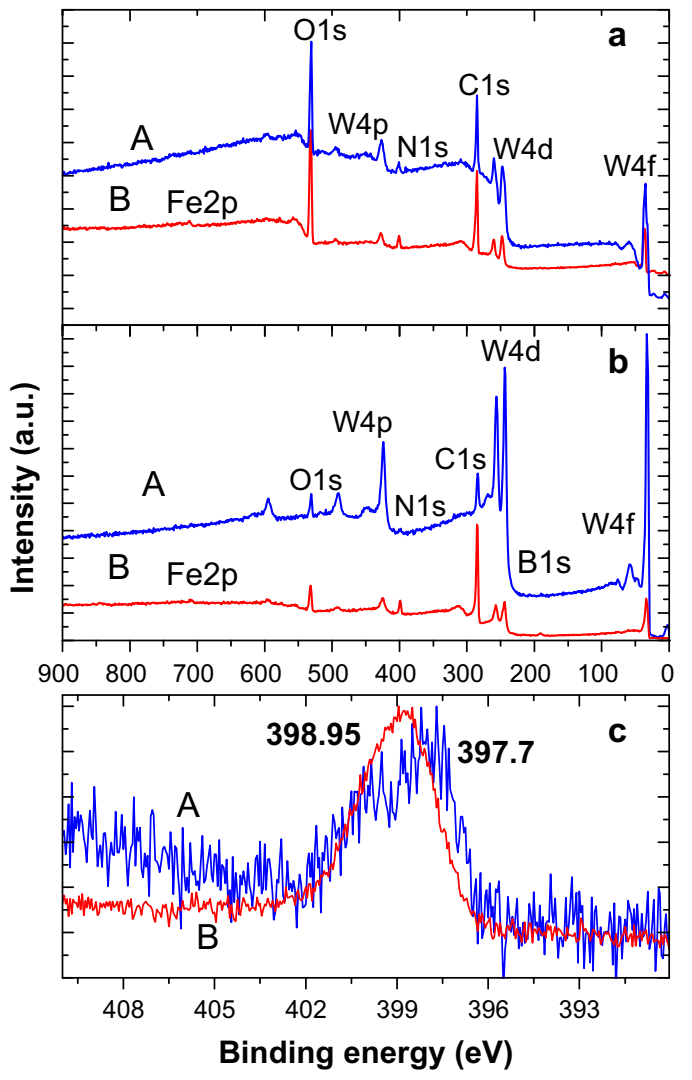

Fig. 4. X-ray photoelectron spectra recorded in areas with and without thick deposit (Points A and B) on the W plate: (a) survey spectrum for the plate after exposure in the tokamak: (b) survey for the surface cleaned by $10 \mathrm{~min}$ sputtering with $\mathrm{Ar}^{+}$; (c) position of the N1s photoelectron line on the surface cleaned with $\mathrm{Ar}^{+}$.

the TEXTOR wall and then re-deposited on the exposed tungsten plate.

\subsection{Neon retention in graphite}

Fig. 5 shows a Rutherford backscattering spectrum recorded for a deposit on a graphite collector probe exposed to the SOL plasma during a neon-assisted discharge contains elements originally removed from the PFC in TEXTOR: carbon, molybdenum, Inconel components $(\mathrm{Ni}+\mathrm{Cr}+\mathrm{Fe})$, silicon, boron and co-deposited fuel species and neon. Typical amount of neon retained in co-deposits formed on graphite collector probes have been found in the range

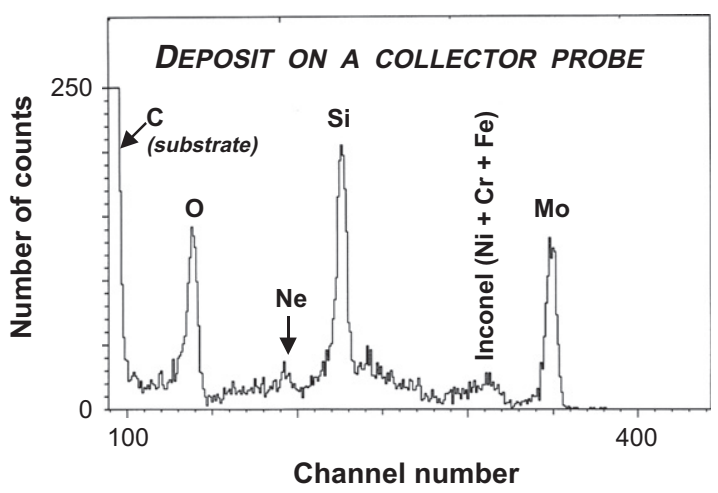

Fig. 5. A Rutherford backscattering spectrum recorded for a graphite collector probe exposed at TEXTOR during discharges with neon injection to plasma edge. 
$2-4 \times 10^{15} \mathrm{~cm}^{-2}$ (for $n_{e}$ above $3 \times 10^{19} \mathrm{~m}^{-3}$ ) which is consistent with the sniffer probe measurements performed during the same discharges [13]. It shows that noble gases are not instantly desorbed from co-deposits.

\section{Concluding remarks}

Comprehensive surface studies of targets exposed to plasma in the presence of nitrogen or neon have shown that both gases are retained in the surface layer of PFC either by co-deposition or compound formation. As determined both by ToF-HIERDA and XPS the thickness of the modified region is small. The formation of tungsten nitrides ( $\mathrm{WN}$ and $\mathrm{W}_{2} \mathrm{~N}$ ) on PFC is reported for the first time. In our opinion, the nitride formation should not be considered as a danger for the tungsten PFC lifetime or integrity in the operation with $\mathrm{N}$-cooling. On hot surfaces only a thin layer would be formed due to a limited implantation range of nitrogen ion. Above $1000{ }^{\circ} \mathrm{C}$ the compound would probably be decomposed, as observed in [24]. Much more important is the "memory" effect showing that from shot-to-shot the amount of nitrogen in the machine is growing. Liberation of nitrogen stored in the wall may lead to the increased erosion and, as a consequence, increased tungsten migration. The other important point is the identification of $\mathrm{WO}_{3}$ on the surface. This is a confirmation of analyses by X-ray diffraction $[22,23]$ done for a castellated tungsten limiter heated to the melting temperature (above $3500{ }^{\circ} \mathrm{C}$ ). Desorption of water from the tungsten bulk was identified as a possible source of oxygen as the increased $\mathrm{O}$ (II) signal was detected by spectroscopy. However, in the case reported in this work, the target temperature was not exceeding $800{ }^{\circ} \mathrm{C}$. Therefore, one can tentatively suggest that even a small local source of oxygen may lead the formation of a volatile oxide which would contribute to the mobility of tungsten in a tokamak.

\section{Acknowledgements}

This work, supported by the European Communities under the contract of Association between EURATOM/VR, was carried out within the framework of the European Fusion Development Agreement. The views and opinions expressed herein do not necessarily reflect those of the European Commission. The work was partly funded under the Contracts 2006-3271 and 621-2009-4138 from the Swedish Research Council (VR).

\section{References}

[1] R. Parker et al., J. Nucl. Mater. 241-243 (1997) 1.

[2] P. Chappuis, J. Nucl. Mater. 241-243 (1997) 27.

[3] Y. Ueda et al., J. Nucl. Mater. 220-222 (1995) 240.

[4] A. Kallenbach et al., Nucl. Fusion 49 (2009) 045007.

[5] A. Kallenbach et al., Plasma Phys. Control. Fusion 52 (2010) 055002.

[6] V. Savchkov, K.-H. Finken, G. Mank, Rev. Sci. Instrum. 73 (2002) 3490.

[7] U. Kruezi et al., Massive Gas Injection in JET - Impact on Wall Conditions, these Proceedings.

[8] F.L. Tabarés et al., Plasma Phys. Control. Fusion 44 (2002) L37.

[9] C. Hopf et al., J. Nucl. Mater. 342 (2005) 141.

[10] T. Schwartz-Selinger et al., J. Nucl. Mater. 363-365 (2007) 174.

[11] P. Sundelin et al., J. Nucl. Mater. 390-391 (2009) 647.

[12] C. Brosset, J. Bardon, E. Gauthier, J. Nucl. Mater. 241-243 (1997) 1093.

[13] Y.M. Kim et al., Vac. Sci. Technol. A20 (2002) 138.

[14] G. Sergienko et al., Phys. Scripta T128 (2007) 81.

[15] V. Philipps et al., Nucl. Fusion 34 (1994) 417.

[16] H.J. Whitlow, G. Possnert, C.S. Petersson, Nucl. Instrum. Methods B 27 (1987) 448 .

[17] M.S. Janson, CONTES Instruction Manual, Report, Uppsala University, 2004.

[18] M. Rubel et al., Phys. Scripta 43 (1991) 508.

[19] M. Rubel et al., J. Nucl. Mater. 220-224 (1995) 536.

[20] Y. Yang et al., Surf. Sci. 600 (2006) 743.

[21] E. Fortuna et al., Phys. Scripta T128 (2007) 162.

[22] M. Psoda et al., J. Nucl. Mater. 386-388 (2009) 740.

[23] M. Rubel et al., Fusion Eng. Des. 83 (2008) 1049.

[24] R.C.V. McGee et al., Appl. Catal. A 284 (2005) 139. 